\title{
Закономерности образования карбидов титана и вольфрама из продуктов электровзрывного разрушения проводников
}

\author{
Ю. О. Адамчук, С. В. Чущак, Л. 3. Богуславский, А. В. Синчук ${ }^{* * *}$ \\ Институт импульсных процессов и технологий НАН Украины, \\ 2. Николаев, 54018, Украина \\ 'e-mail: iipt@iipt.com.ua , ${ }^{* *}$ e-mail: Synchuk.A.V@nas.gov.ua \\ Поступила в редакцию 01.04.2021 \\ После доработки 22.04.2021 \\ Принята к публикации 26.04.2021
}

\begin{abstract}
Выполнена серия электрических взрывов одинарных и соединенных в скрутки проводников различного диаметра из титана (Ti) и вольфрама (W) в пропан-бутане. Анализ электрофизических характеристик взрыва показал, что процесс резистивного нагрева проводников характеризуется двумя монотонно восходящими участками на кривых напряжения и тока, разделенными пологим отрезком (плато), который соответствует относительно стабильному удельному электросопротивлению рефракторных металлов в жидком состоянии. Введенная в проводник на стадии резистивного нагрева энергия, которая может быть выше или ниже энергии сублимации проводника и регулироваться путем изменения внешних параметров разрядного контура, является ключевым показателем, определяющим структурно-фазовое состояние продуктов разрушения и химического взаимодействия проводника. Реализованы условия, при которых микро- и наноразмерные порошковые продукты электровзрыва не содержат остаточных металлов и полностью состоят из карбидных фаз (ТiC со средней микротвердостью 29580 МПа - при взрыве титановых проводников и смеси $\mathrm{W}_{2} \mathrm{C}+\mathrm{WC}_{1-\mathrm{x}}$, в которой доминирует стабилизированный высокотемпературный нестехиометрический кубический карбид $\mathrm{WC}_{1-\mathrm{x}}$, со средней микротвердостью 16770 МПа - при взрыве проводников из вольфрама).
\end{abstract}

Ключевые слова: электрический взрыв проводника, рефракторные металлы, скорость введения энергии, энергия сублимации, порошок, карбиды

УДК 537.523:53.097:621.763

https://doi.org/10.52577/eom.2021.57.6.50 ВВЕДЕНИЕ

Карбиды переходных $d$-металлов являются самыми тугоплавкими и самыми твердыми из химических соединений. Например, карбид титана ТiC, который проявляет стойкость к абразивному износу и агрессивным средам, включая биологические среды, обладает высокой электрои теплопроводностью и находит широкое применение в технике для изготовления защитных покрытий металлов, в качестве компонентов и легирующих добавок безвольфрамовых твердых сплавов, в стоматологии $[1,2]$. По сравнению с ним карбиды вольфрама $\mathrm{WC}$ и $\mathrm{W}_{2} \mathrm{C}$ имеют более низкую температуру плавления и меньшую твердость, которая, однако, является стабильной (особенно для высшего карбида WC) и мало изменяется с повышением температуры. Благодаря этому свойству монокарбид вольфрама долгие годы является основной составляющей инструментальных износостойких и других функциональных материалов [3]. На сегодняшний день свойства карбидов WC и

$\mathrm{W}_{2} \mathrm{C}$, которые имеют гексагональную решетку, достаточно хорошо изучены и их промышленное получение не представляет трудностей. Однако в системе W-C существует еще одна, менее распространенная, кубическая фаза со стехиометрией $\mathrm{WC}_{1-\mathrm{x}}$, которая отличается узким диапазоном температурной стабильности (приблизительно 2790-3060 К), что делает ее более трудной для синтеза промышленными методами в сравнении с гексагональными модификациями [4]. Именно этой фазе в последнее время уделяется пристальное внимание в связи с тем, что кубический карбид обладает высокой поверхностной реакционной активностью и, хотя сам по каталитическим свойствам уступает платине, значительно усиливает ее каталитическое действие при совместном использовании в процессах получения водорода и крекинга нефти $[5,6]$. Полагают [7], что кубическую фазу $\mathrm{WC}_{1-\mathrm{x}}$ можно зафиксировать при комнатной температуре путем закалки от жидкого состояния со скоростью $10^{8}-10^{11} \mathrm{~K} / \mathrm{c}$ или физическими (физико-химическими) методами 


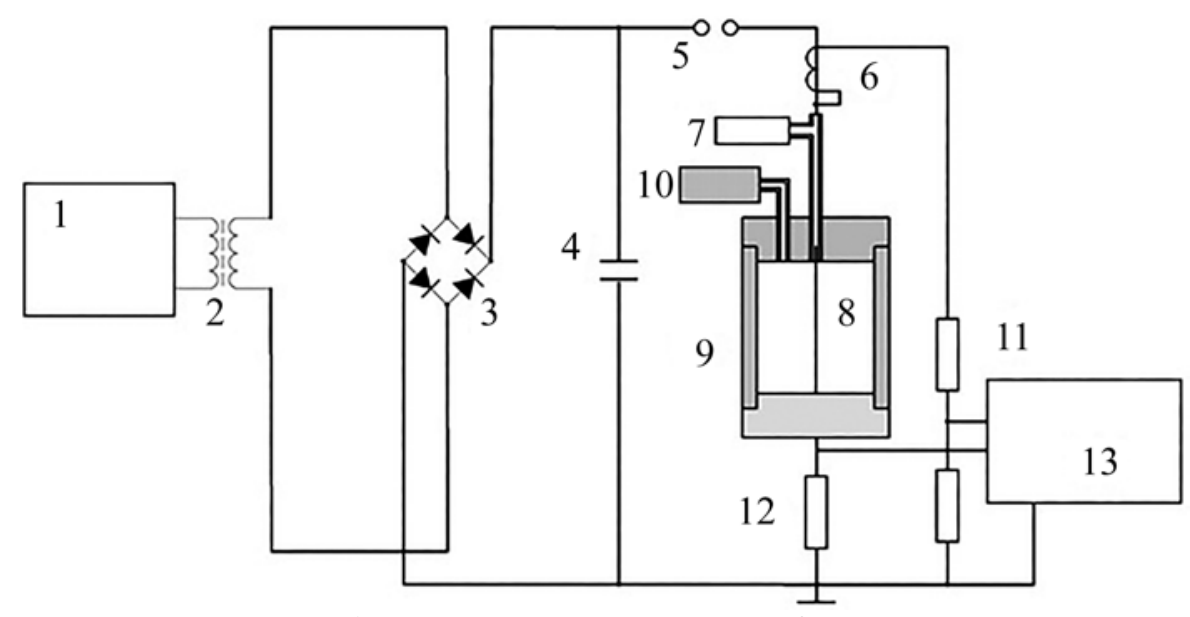

Рис. 1. Схема экспериментальной установки: 1 - высокочастотный инвертор; 2 - высоковольтный высокочастотный трансформатор; 3 - выпрямитель; 4 - конденсатор; 5 - воздушный разрядник; 6 - катушка компенсации; 7 - пропан-бутан; 8 - проводник; 9 - реактор; 10 - фильтр; 11 -делитель напряжения; 12 - шунт; 13 - осциллограф.

получения порошков, которые основываются на превращениях испарения, конденсации, возгонки, резкого нагрева или охлаждения.

Электрический взрыв проводника (ЭВП) в газообразной среде, содержащей углерод, является комбинированным процессом, где распыление металла сопровождается высокотемпературным пиролизом газа, а образованные активные атомы углерода участвуют в синтезе химических соединений с металлом проводника. Преобразование материала проводника осуществляется в экстремальных неравновесных условиях, связанных со скоростным нагревом металла, ионизацией, действием электро-магнитных полей, скоростными химическими реакциями, скоростным охлаждением продуктов химического взаимодействия. Выполненные на современном техническом уровне работы (например, [8, 9]) показывают, что такие условия синтеза делегируют образованным продуктам химических реакций свойства, отличные от структуры и свойств порошков, полученных другими способами.

Но процесс ЭВП в органическом газе, прежде всего тугоплавких проводников, еще требует изучения. Взорвать тугоплавкий проводник таким образом, чтобы его материал 100-процентно был задействован в образовании химических соединений, гораздо сложнее, чем легкоплавкий проводник с хорошей, близкой к меди электропроводностью. Ведь образование химических соединений ограничивается строго определенным диапазоном термодинамических параметров: давлением, температурой, концентрацией продуктов диссоциации в газообразной фазе, наличием или отсутствием охлажденных продуктов химического синтеза, частиц твердого углерода, остаточных частиц металла. Таким образом, карбидообразование будет определяться многими факторами, но в первую очередь, режимами ЭВП, которые обеспечивают то или иное фазовое состояние продуктов разрушения проводника, и физико-химическими характеристиками таких рефракторных металлов, как Ті и W.

Цель этой работы - определить условия, при которых продукты ЭВП содержат максимальное количество карбидных фаз титана и вольфрама.

Схема экспериментальной установки для реализации ЭВП, где источником энергии является высоковольтный генератор импульсных токов с емкостным накопителем, приведена на рис. 1. Генератор подключен к электроду с коаксиальным отверстием, через которое вручную или автоматически можно подавать в межэлектродный промежуток проводник любой конфигурации (проволока прямая, спиральная, свернутая фольга), и противоэлектроду, к которому примыкает проводник. Подрывались как одиночные диаметром $d$, так и собранные в тройную скрутку титановые и вольфрамовые проводники (провода), которые имели длину, тождественную величине межэлектродного промежутка, то есть 80 мм. Все взрывы реализованы в соответствии с режимами (табл. 1), которые разнятся между собой энергоемкостью и скоростью ввода в проводник энергии (электрической мощностью). Сочетание регулируемых параметров генератора - начального напряжения и емкости конденсатора - подбиралось таким образом, чтобы в проводники можно было вводить электрическую энергию как меньше, так и больше их энергии сублимации.

Органический газообразный источник углерода - пропан-бутан подавался, а газообразные продукты пиролиза выводились через каналы в изоляционной крышке. В разрядной камере поддерживалось обычное атмосферное давление газа с целью предупреждения негативного влияния периферийных дуг - явления, часто сопровождающего ЭВП в вакууме и разре- 
Таблица 1. Режимы ЭВП

\begin{tabular}{|c|c|c|c|}
\hline № режима & $\begin{array}{c}\text { Начальное напряжение } U_{0}, \\
\text { кВ }\end{array}$ & $\begin{array}{c}\text { Емкость конденсатора } C, \\
\text { мкФ }\end{array}$ & $\begin{array}{c}\text { Накопленная энергия } E_{0}, \\
\text { кДж }\end{array}$ \\
\hline 1 & 8 & 50 & 1,6 \\
\hline 2 & 12 & 25 & 1,8 \\
\hline 3 & 25 & 5 & 1,6 \\
\hline 4 & 30 & 5 & 2,25 \\
\hline 5 & 35 & 5 & 3,1 \\
\hline 6 & 40 & 5 & 4 \\
\hline
\end{tabular}

женном газе. Шунтирующее действие периферийных дуг мешает процессу ввода энергии в проводник и соответственно вызывает необходимость увеличивать энерговвод на резистивной стадии, а при низком давлении окружающего газа его электрическая прочность уменьшается, вследствие чего образование шунтирующего дугового разряда облегчается. При атмосферном давлении вероятность возникновения этого нежелательного явления уменьшается.

Для контроля электрических характеристик разрядного контура использованы делитель напряжения и шунт, подключенные к цифровому осциллографу Witting Technologies W2012, с помощью которого регистрировались временные зависимости напряжения $u(t)$ и тока $i(t)$. Активная составляющая тока вычленялась в условиях эксперимента за счет компенсации индуктивной составляющей с помощью катушки компенсации, выполненной в виде соленоида и включенной последовательно с делителем напряжения в его высоковольтное плечо. Количество витков определяло величину компенсационной э.д.с., а контроль компенсации осуществлялся путем короткого замыкания разрядного промежутка. Собственное сопротивление разрядного контура составляло 0,05 Ом, что существенно меньше величины первоначального сопротивления проводника. Таким образом, электрическая энергия $E$, введенная в проводник на момент взрыва, рассчитывалась по уравнению:

$$
E=\int_{0}^{t_{p}} u(t) \times i(t) d t
$$

где $t_{p}$ - время резистивного нагревания проводника, отождествленное с пиком перенапряжения, с.

Для проведения рентгенофазового анализа порошков применен дифрактометр ДРОН-4-07 с медным анодом (длина волны $\mathrm{Cu}_{\mathrm{K \alpha}}$-излучения

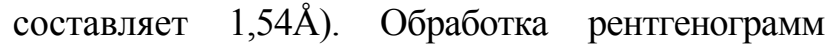
осуществлялась с использованием компьютерной программы QuaIX, которая использует международную базу данных JSPDS. Для определения количества карбидной фазы в составе двухкомпонентного порошка $V_{\kappa}$ использовали соотношение:

$$
V_{\kappa}=\frac{I_{\kappa} / P_{\kappa}}{I_{\kappa} / P_{\kappa}+I_{M e} / P_{M e}} \times 100 \%,
$$

где $I_{\kappa}, I_{M e}-$ интегральные интенсивности линий карбидной фазы и фазы, соответствующей металлу проводника на дифрактограммах (в тексте упоминается как остаточный металлический Ті или $\mathrm{W}) ; P_{\kappa}, P_{M e}$ - факторы повторяемости для соответствующих отражений.

\section{ОСОБЕННОСТИ ЭВП РЕФРАКТОРНЫХ МЕТАЛЛОВ}

Как известно, ЭВП - физическое явление, связанное с рядом последовательных принципиальных изменений физического состояния вещества проводника, который в зависимости от осажденной в нем энергии на момент потери целостности может быть жидким или газообразным, с последующим электрическим пробоем межэлектродного промежутка. Кроме того, ЭВП в органическом газе под действием плазмы разряда сопровождается высокотемпературным пиролизом с разложением газа на атомарный углерод, который участвует в образовании химических соединений с металлом проводника, и водород (или низшие углеводороды). Поэтому, когда речь идет о дисперсных, наноразмерных продуктах химических реакций, логично думать, что они могут образовываться как раз тогда, когда оба реагирующих элемента находятся в газообразном состоянии, где скоростная диффузия способствует протеканию химических реакций. В частности, образование карбидных фаз из полностью газообразных компонентов возможно при температурах, превышающих точку кипения материала проводника, равную соответственно $3560 \mathrm{~K}$ для титана и $5933 \mathrm{~K}$ для вольфрама. При более высоких температурах возможна одновременная деструкция химических веществ, а при более низких температурах, в диапазоне жидкого и твердого состояния проводника, скорости химических реакций малы. Чтобы перевести проводник, который взрывается, в газообразное состояние, необходимо в него ввести электри- 
Таблица 2. Характеристики проводников $d=0,3$ мм

\begin{tabular}{|l|c|c|}
\hline \multicolumn{1}{|c|}{ Материал } & $\mathrm{Ti}$ & $\mathrm{W}$ \\
\hline Масса одинарной проволоки, г & 0,025 & 0,22 \\
\hline$E_{c}$ одинарной проволоки, Дж & 300 & 1144,2 \\
\hline Масса скрутки, г & 0,075 & 0,66 \\
\hline Электрическое сопротивление скрутки при $20^{\circ} \mathrm{C}$, Ом & 0,124 & 0,017 \\
\hline$E_{c}$ скрутки, Дж & 900 & 3432,6 \\
\hline
\end{tabular}

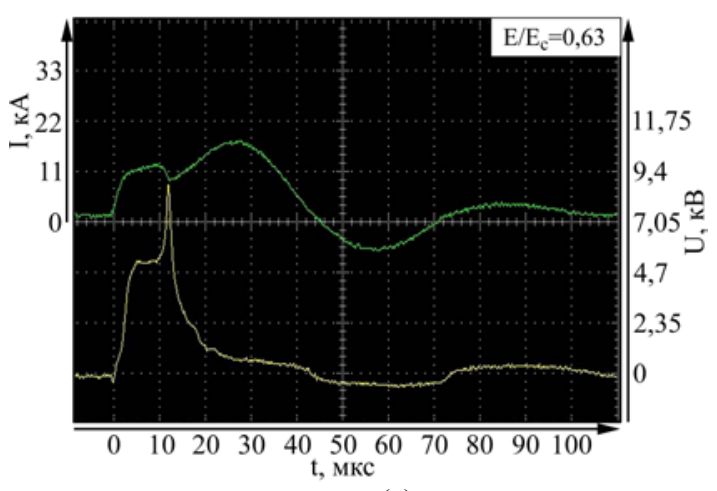

(a)

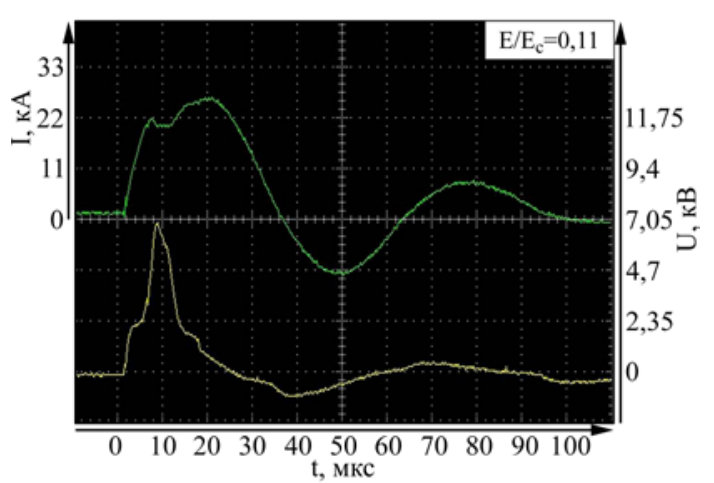

(б)

Рис. 2. Осциллограммы электровзрыва скруток Ті (а) и W (б), режим 1.

ческую энергию $E$, как минимум равную энергии сублимации $E_{c}$.

В табл. 2 приведены значения $E_{c}$ для одинарных проводников из Ті и $\mathrm{W}$ диаметром $d=0,3$ мм и скруток, состоящих из трех таких проводников, а на рис. 2 - осциллограммы, соответствующие этим скруткам, взорванным при одинаковых начальных значениях напряжения и емкости. Рассматривая соотношение $E / E_{c}$, можно констатировать, что ни одна из скруток не была доведена до стадии полного испарения, поскольку в относительно толстые проводники за короткое время резистивного нагревания вводится недостаточное для этого количество электрической энергии (в вольфрамовые скрутки - едва ли четверть необходимого количества). Временные зависимости напряжения отличает особенность в виде пологого отрезка с незначительным углом наклона относительно оси абсцисс $(u=5,3-5,5$ кВ для $\mathrm{Ti}$ и $u=1,95-2,35$ кВ для W), так называемое плато, которое характеризует пребывание проводника в жидком состоянии и объясняется стабильностью сопротивления жидких рефракторных металлов в широком температурном диапазоне. В частности, расчет по экспериментальным осциллограммам показывает, что на начало плавления и начало испарения сопротивление скрутки из Ті составляет соответственно 0,48 и 0,5 Ом, то есть почти не изменяется. Для скрутки из W сопротивление в температурном интервале существования расплава несколько возрастает - с 0,09 Ом до 0,12 Ом, однако этот рост все равно происходит значительно медленнее, чем в металлах, которые хорошо проводят электрический ток (к примеру, меди, удельное сопротивление которой в темпе- ратурном интервале жидкого состояния, по данным [10], возрастает в 2,3 раза).

Характеризуя временную зависимость тока, можно видеть, что за пиком перенапряжения для проводников ток резко возрастает, обозначая дуговую стадию разряда, а после срыва напряжения имеет привычную форму затухающей синусоиды. Наличие дуговой стадии ЭВП, вероятнее всего, объясняется неоднородностью нагрева относительно толстых, по сравнению с одинарными проводниками, скруток, что провоцирует первоочередное испарение поверхностных слоев и развитие поверхностного разряда. Может срабатывать также развитая поверхностная электронная эмиссия, благодаря которой дуговая стадия начинает развиваться, когда рефракторные металлы находятся еще в жидком, иногда даже в твердом состоянии. И поскольку ток течет по поверхностным парам, резистивный нагрев сердцевины прекращается, а дальнейший процесс испарения полностью контролируется взаимодействием горячей дуги с более холодным ядром проводника. Такой сценарий ЭВП для Ті экспериментально подтвержден, например, в [11], а для W, на основе которого выполняются проволочные сборки Z-пинча, в [12].

Таким образом, введение энергии, достаточной для испарения проводника, в металлы рефракторной группы, куда относятся Ті и $\mathrm{W}$, осложняется из-за развития электронной эмиссии с поверхности и преждевременного начала дуговой стадии. Из-за малого количества введенной энергии, которой не хватает, чтобы расплавить проводник, его сердцевина будет оставаться в твердом состоянии или частично 


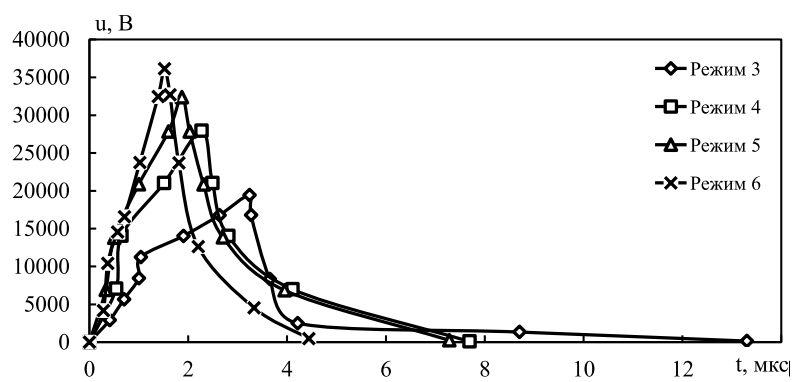

(a)

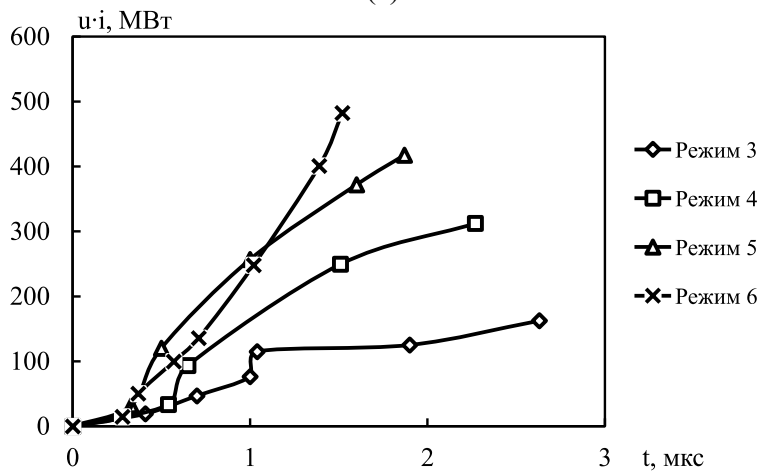

(в)

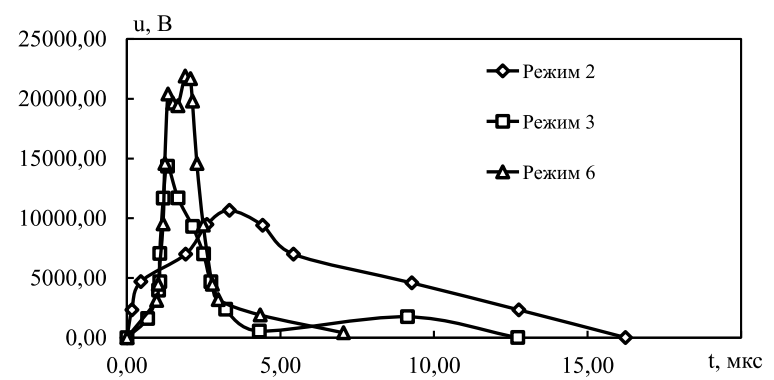

(б)

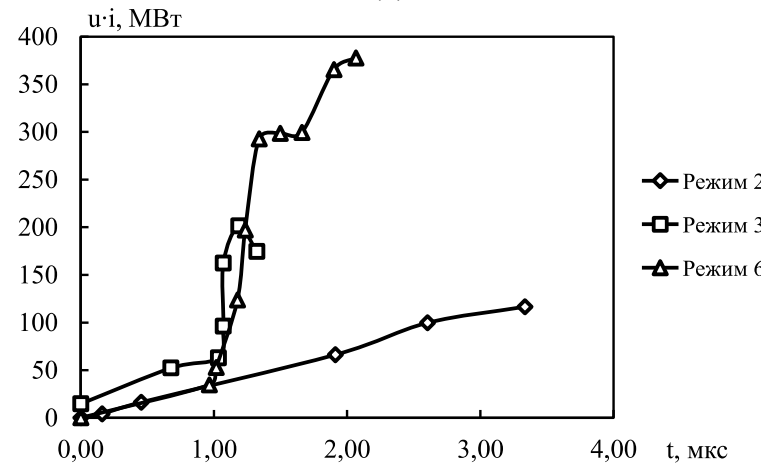

(г)

Рис. 3. Временные зависимости напряжения и электрической мощности при взрыве одинарных проводников $d=0,3$ мм из $\mathrm{Ti}(\mathrm{a}),($ в) и $\mathrm{W}($ (б), (г).

распадаться на промежуточном уровне (больше, чем энергия плавления, но меньше, чем энергия испарения) на микрокапли горячей жидкости или кластеры жидкости субмикронного размера. Указанные на рис. 2 величины введенной энергии $E<E_{c}$ дают возможность полагать, что продуктами распада титановых и вольфрамовых скруток являются микрокапли расплава, а продуктами химических реакций - карбиды такого же размера или композиты с карбидной поверхностью и металлической сердцевиной. Следует напомнить, что длина проводников, используемых в экспериментальных исследованиях, тождественная длине межэлектродного промежутка, составляла 80 мм. То есть в продуктах ЭВП могут присутствовать и более крупные частицы остаточного металла, образование которых определяется краевыми эффектами - взрывом концов проводника при более низкой напряженности электрического поля.

\section{ВЛИЯНИЕ СКОРОСТИ ВВЕДЕНИЯ В ПРОВОДНИК ЭНЕРГИИ (ЭЛЕКТРИЧЕСКОЙ МОЩНОСТИ)}

Безусловно, получение полностью газообразных продуктов ЭВП облегчается, если вместо скруток взрывать одинарные проводники и увеличивать скорость энерговвода в расчете на инерционный характер испарения материала проводника. Определенная по осциллограммам взрыва скруток (рис. 2) электрическая мощность, которую обеспечивает режим 1, в конечной точке восходящей ветви, то есть в начальной точке плавления проводника, составляла 56,1 МВт для титана и 23 МВт для вольфрама. Для сравнения на рис. 3 приведены временные зависимости напряжения взрыва одинарных проводников и режимов 2-6, построенные по осциллограммам первого полупериода ЭВП, а также графики нарастания электрической мощности на восходящем прямолинейном отрезке $i(t)$, предшествующем образованию плато. Можно видеть, что с увеличением $U_{0}$ и соответственно энергии, накопленной конденсатором $E_{0}$, ширина первого полупериода напряжения значительно уменьшается, а пик перенапряжения, за которым следует резкий обвал, сдвигается вверх и влево, то есть в сторону меньшего времени, что соответствует увеличению скорости введения в проводник электрической энергии. В диапазоне начальных напряжений зарядки конденсатора $U_{0}=25-40$ кВ пиковые значения перенапряжения, которое возникает при взрыве титановой проволоки, достигают $78-93 \% \quad U_{0}$, а первая четверть периода, характеризующая стадию резистивного нагрева проводника, сокращается почти вдвое. Пиковые перенапряжения, характерные для взрыва вольфрамовой проволоки, несколько ниже относительно начального напряжения зарядки конденсатора и составляют $55-58 \% U_{0}$, время резистивного нагрева проводника по мере 


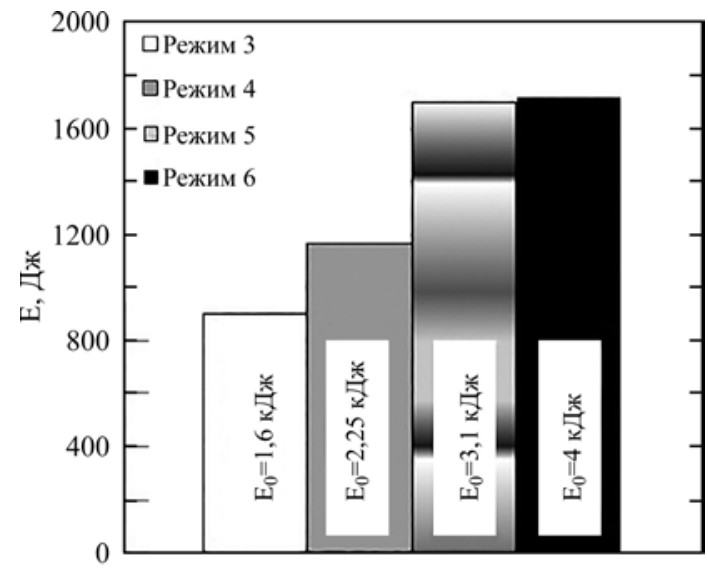

(a)

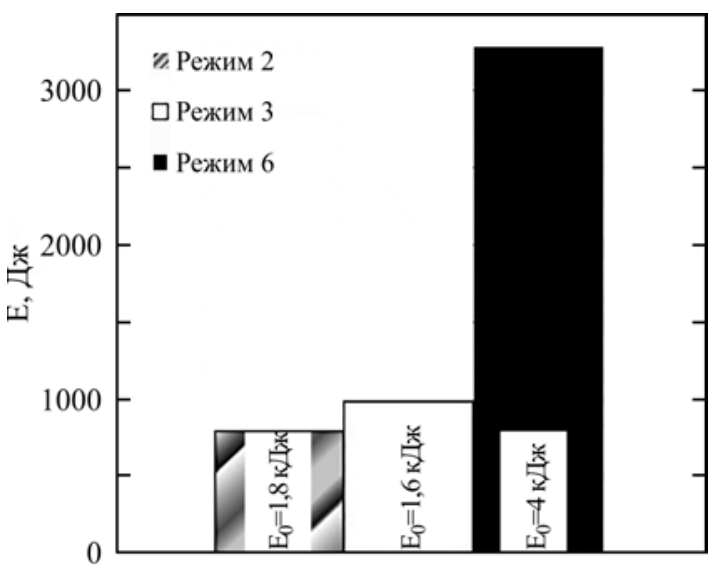

(б)

Рис. 4. Энергия, введенная на момент взрыва в одинарный проводник $d=0,3$ мм из Ti (а) и W (б).

Таблица 3. Энергетическая эффективность ЭВП. Одинарные проводники $d=0,3$ мм

\begin{tabular}{|c|c|c|c|c|}
\hline \multirow{2}{*}{ № режима } & \multicolumn{2}{|c|}{ Ti } & \multicolumn{2}{c|}{$\mathrm{W}$} \\
\cline { 2 - 5 } & $E / E_{c}$ & $E / E_{0}$ & $E / E_{c}$ & $E / E_{0}$ \\
\hline 1 & 0,87 & 0,31 & 0,53 & 0,36 \\
\hline 2 & 0,98 & 0,35 & 0,6 & 0,4 \\
\hline 3 & 3 & 0,56 & 0,88 & - \\
\hline 4 & 3,83 & 0,51 & - & - \\
\hline 5 & 5,5 & 0,53 & - & 0,8 \\
\hline 6 & 5,83 & 0,44 & 2,85 & \\
\hline
\end{tabular}

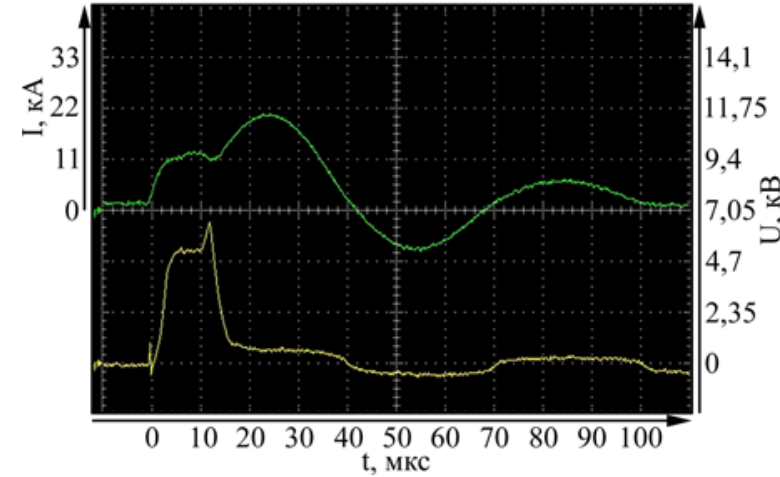

(a)

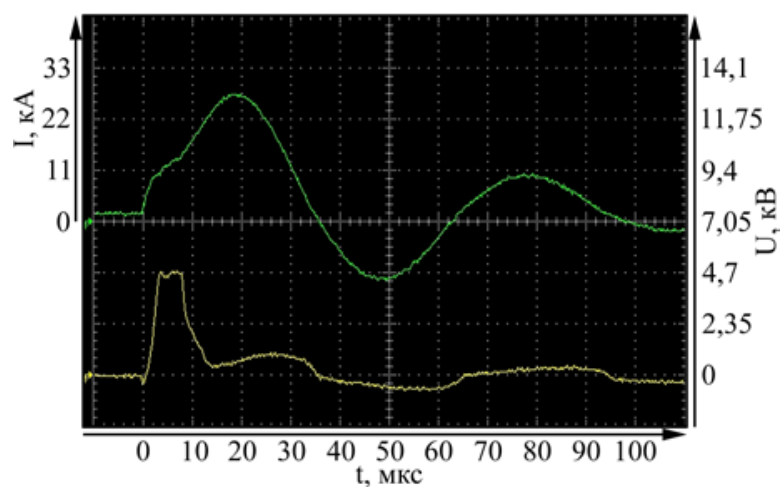

(б)

Рис. 5. Осциллограммы взрыва скруток из Ті без нагрева (а) и с нагревом до $700{ }^{\circ} \mathrm{C}$ (б).

роста $U_{0}$ также сокращается, но не так ощутимо по сравнению с ЭВП титана.

Данные рис. 4 и табл. 3 дают возможность проанализировать, какое количество энергии $E$ вводится до взрыва в одинарные проводники тугоплавких металлов одинаковой геометрии и какая доля энергии $E_{0}$, накопленной конденсатором, используется для реализации ЭВП. $\mathrm{B}$ проводники из $\mathrm{Ti}$ при напряжении $U_{0}=25-40$ кВ на стадии резистивного нагрева можно ввести порцию энергии, превышающей энергию сублимации $E_{c}$ проводника в несколько раз, используя для этого только 0,44-0,56\% энергии, накопленной конденсатором. Для реализации ЭВП с полным испарением более тугоплавкого W такая возможность уверенно реализуется c повышением напряжения до $U_{0}=40$ кВ при использовании $80 \%$ энергии, накопленной конденсатором. Таким образом, даже с учетом отсутствия в табл. 3 эксперимен- тальных данных для некоторых режимов можно констатировать, что при одинаковых прочих условиях реализация ЭВП проводников из Ті требует в несколько раз меньшей энергии.

\section{ВЛИЯНИЕ ТЕМПЕРАТУРЫ ПРОВОДНИКА}

В ходе работы было также исследовано влияние начальной температуры проводника на электрические характеристики ЭВП. Были взяты две идентичные скрутки проводов Ті. На рис. 5а приведены осциллограммы ЭВП, когда скрутка имела начальную комнатную температуру, а на рис. $5 б$ - когда скрутка перед подачей в реактор предварительно нагревалась до температуры $700^{\circ} \mathrm{C}$, то есть на $42 \%$ от температуры плавления $\mathrm{Ti}$, и изотермически выдерживалась при этой температуре в течение 10 минут. Параметры разрядного контура были одинаковы в обоих случаях, взрыв производился в режиме 1 . 

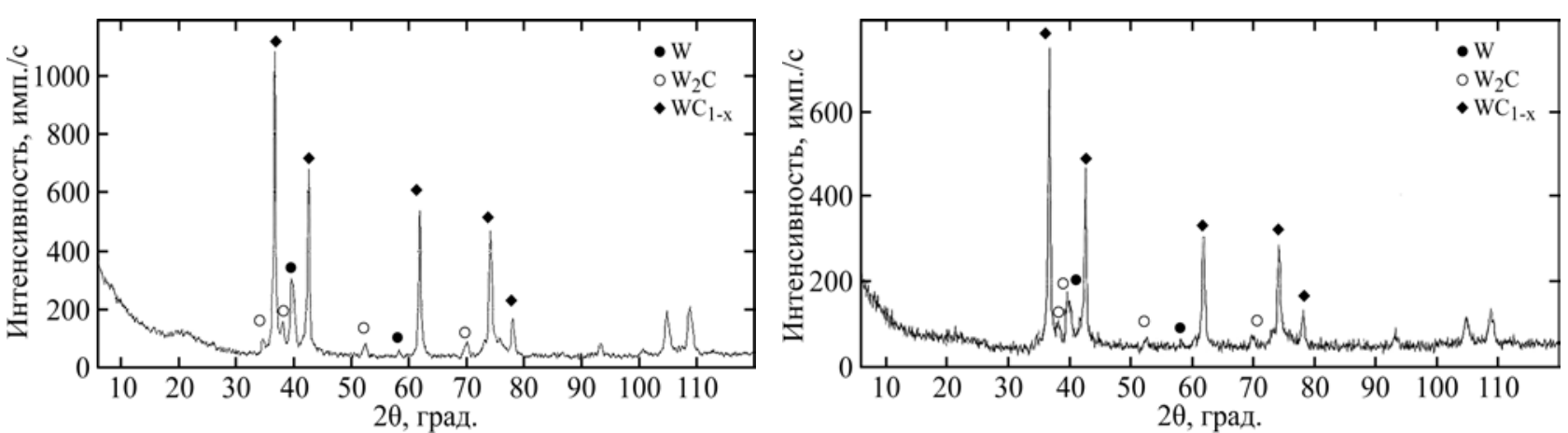

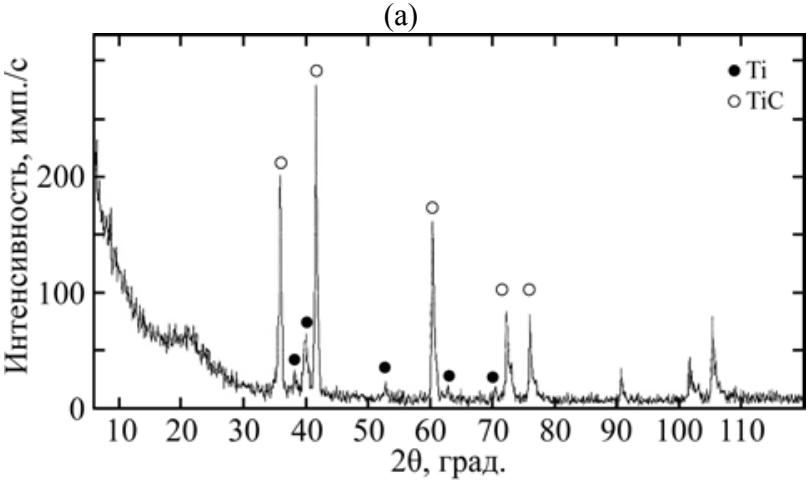

(в)

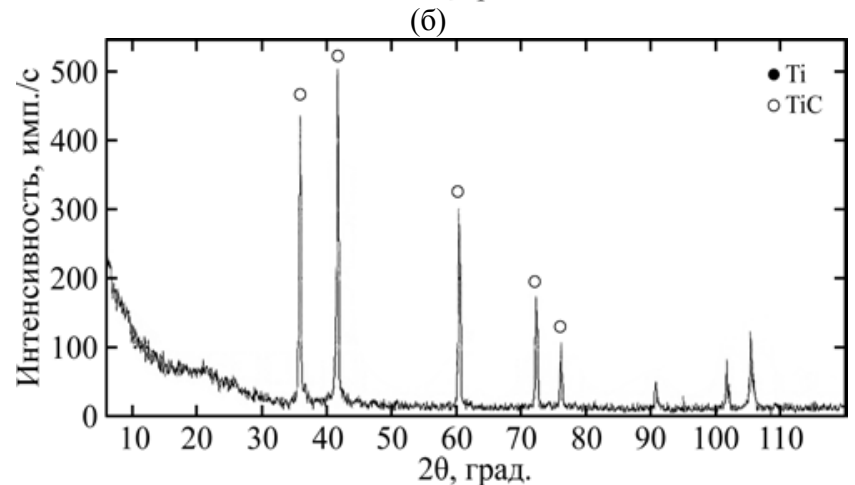

(г)

Рис. 6. Дифрактограммы продуктов взрыва проводников $d=0,3$ мм из $\mathrm{W}$ (а, б) и $\mathrm{Ti}(\mathrm{B}$, г), режим 2 (а), (в) и режим 6 (б), (г).

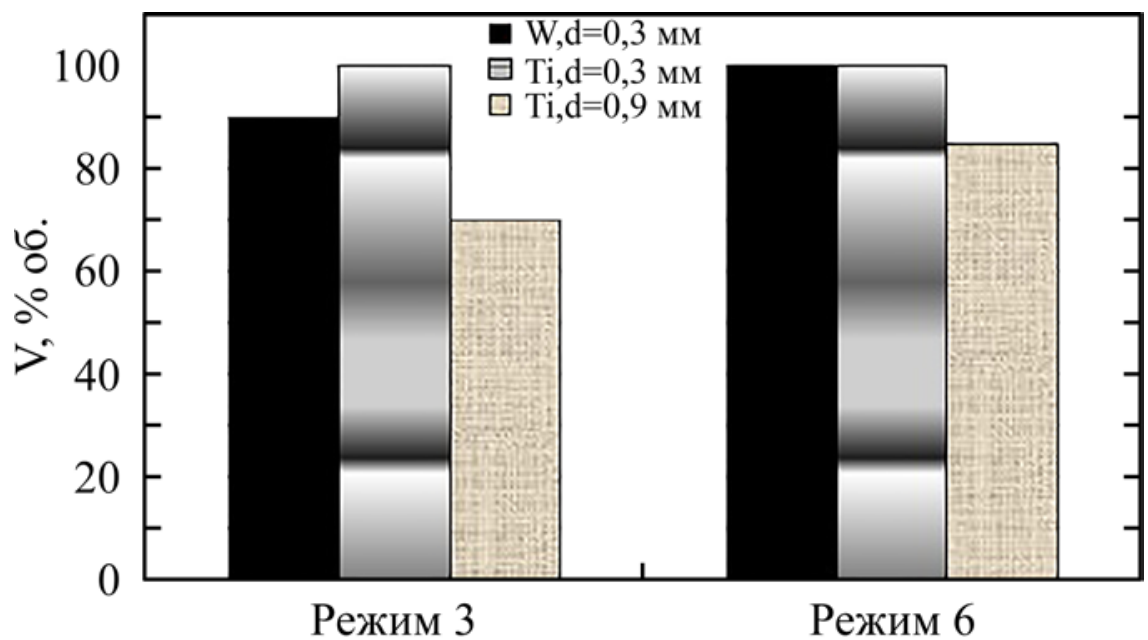

Рис. 7. Содержание карбидных фаз в продуктах ЭВП.

Сравнение данных показывает, что переход предварительно прогретого внешним нагревателем проводника в жидкое состояние действительно требует меньших затрат электроэнергии, в то же время пребывание в жидком состоянии несколько сокращается. При этом взрыв сопровождается ранним развитием значительно более мощной (чем без нагрева проводника) дуговой стадии, что может объясняться в том числе активацией имеющихся на поверхности проводника дефектов структуры и диффузионным перемещением на поверхность дефектов структуры в ходе предварительного нагрева. Таким образом, имеющиеся в литературе сведения о влиянии предварительного нагрева проводников на ЭВП [13], а именно на задержку пробоя межэлектродного промежутка и увеличение энергоосаждения в проводник за счет увеличения продолжительности резистивной стадии его нагрева, пока не подтверждаются, хотя, надо признать, требуют более детальных исследований.

\section{ПОРОШКОВЫЕ ПРОДУКТЫ ЭВП}

Данные рис. 6 свидетельствуют, что при $E / E_{c}<1$ порошковые продукты ЭВП, которые оседают на дно реактора, представляют собой многокомпонентную смесь - содержат в зависимости от режимов ЭВП и геометрических характеристик проводника как чистый металл, так и карбидные фазы. Зато порошки, полученные при 

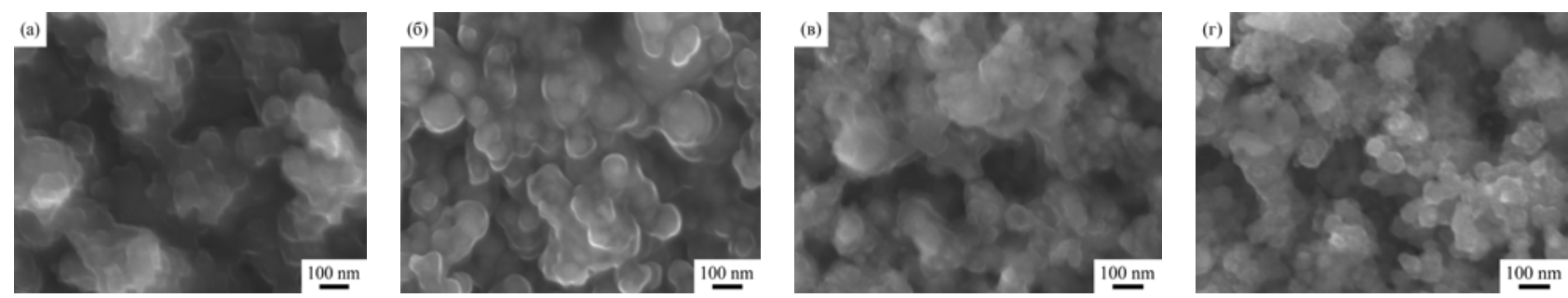

Рис. 8. Структура порошковых продуктов взрыва одинарных проводников $d=0,3$ мм из Тi (а), (б) и $\mathrm{W}$ (в), (г), режим 1 (а), (в) и режим 2 (б), (г).

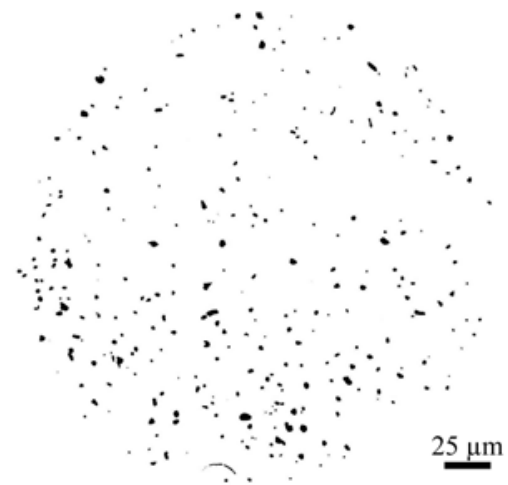

(a)

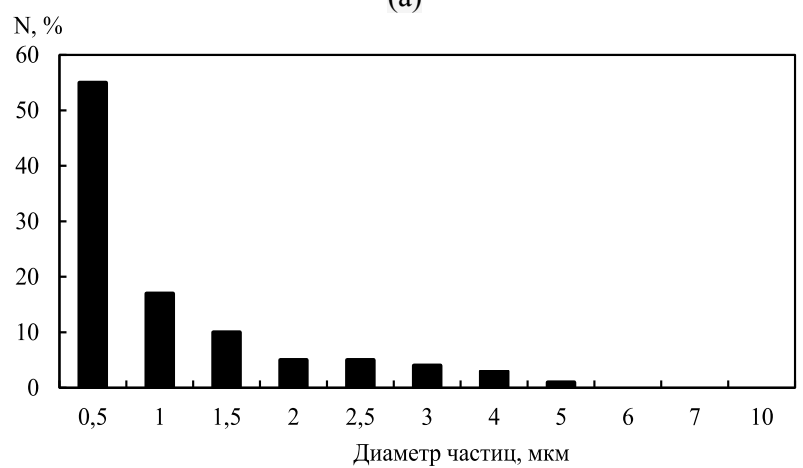

(в)

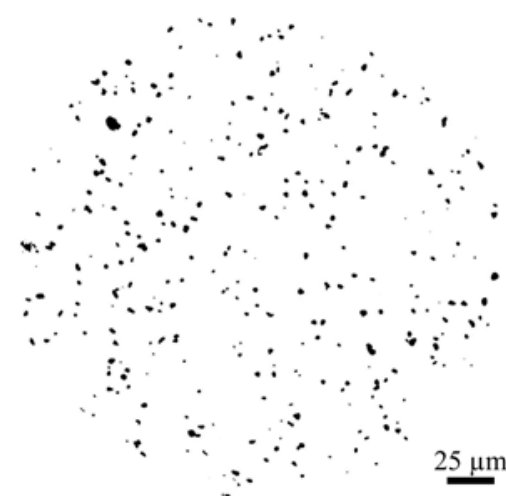

(б)

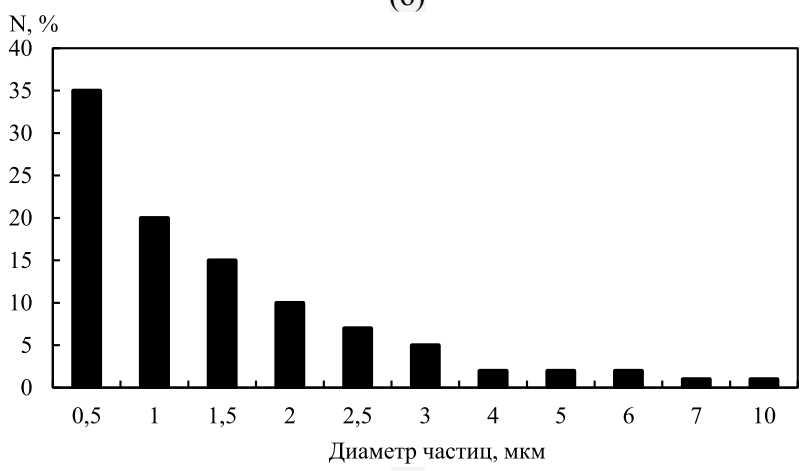

(г)

Рис. 9. Оптические изображения (а), (б) и распределение по размерам порошковых продуктов взрыва одинарных проводников из Ti $d=0,3$ мм (а) и $d=0,9$ мм (б), режим 2.

$E / E_{c} \geq 1$, представляют собой исключительно карбидные фазы. ТіС является единственной карбидной фазой, образующейся вследствие химического взаимодействия материала титанового проводника с углеродом. После ЭВП вольфрамовой проволоки образуются два карбида, причем оба высокотемпературные - $\mathrm{W}_{2} \mathrm{C}$ и нестехиометрический карбид $\mathrm{WC}_{1-\mathrm{x}}$, который доминирует по количеству в порошковой смеси. Очевидно, высокие температуры образования неравновесной плазмы в углеродсодержащем газе и быстрое охлаждение порошков, которое препятствует их структурной перестройке, обеспечивают синтез и стабилизацию при комнатной температуре именно высокотемпературных модификаций $\mathrm{W}_{2} \mathrm{C}$ и $\mathrm{WC}_{1-\mathrm{x}}$.

Рис. 7 демонстрирует, как меняется фазовый состав продуктов ЭВП, то есть количество карбидных и остаточных металлических фаз, по мере роста введенной в проводник энергии, а соответственно и соотношения $E / E_{c}$. Можно видеть, что содержание остаточных металлов в порошках уменьшается, а содержание карбидов увеличивается. В режиме 6 порошки, образованные в результате ЭВП малого диаметра $(d=0,3$ мм), состоят исключительно из карбидов, а вот полностью перевести в карбидную фазу продукты взрыва более толстых проводников $(d=0,9$ мм) не удается.

Таким образом, величина введенной в проводник энергии является значимым фактором влияния на синтез химических соединений при ЭВП. Как свидетельствуют экспериментальные значения $E / E_{c}$, взаимодействие химически активных атомов окружающей среды с материалом проводника происходит преимущественно в жидком и газообразном состоянии.

Относительно размеров синтезированных карбидов можно сказать следующее. Если синтез проходит в жидкой фазе, то при температуре, когда энергия Гиббса твердой фазы меньше нуля, химические соединения сначала образуются на поверхности металлических капель. Поскольку поверхностные карбиды 
имеют более высокую температуру плавления и кипения по сравнению с металлической сердцевиной, то вероятность коагуляции капель уменьшается, что должно способствовать образованию более дисперсных продуктов ЭВП.

Исследование порошков с помощью средств электронной микроскопии (рис. 8) обнаруживает сферическую форму и гладкую поверхность частиц порошка. Наряду с микронной фракцией в порошке есть большое количество частиц размером менее 100 нм. Мелкие частицы имеют склонность оседать на более крупных с образованием отдельных агломератов, но все частицы, независимо от размера, сферические, что указывает на прохождение проводника через жидкое состояние и действие сил поверхностного натяжения. Чем больше энергии введено в проводник, тем позже наступает переохлаждение, тем меньше плотность пара в момент зародышеобразования и соответственно больше возникает центров конденсации. Конечный диаметр частиц при этом уменьшается. Повышение энергетики ЭВП также увеличивало скорость расширения продуктов взрыва, способствовало уменьшению среднего размера частиц разрушенного проводника.

Размер частиц порошка зависит и от диаметра проводника и, как показывает рис. 9, при равном значении введенной энергии дисперсность порошка увеличивается с уменьшением диаметра проводника. Продукты взрыва проходят одинаковые фазовые состояния за время, пропорциональное начальному диаметру проводника, а продолжительность процесса коагуляции, которая определяется термодинамическими и гидродинамическими условиями, также пропорциональна диаметру проводника.

На дисперсность продуктов взрыва резистивных проводников, очевидно, влияет и дуговой разряд. В случае резистивного проводника дуговой разряд охватывает весь его объем, в отличие от металлов, которые отключают ток в контуре при ЭВП (медь, алюминий) и для которых дуговой разряд проходит локализовано. Дуговой разряд удлиняет во времени коагуляцию первичных продуктов взрыва проводника в процессе их разлета и охлаждения, что также способствует уменьшению размеров порошковых продуктов.

Среднее значение микротвердости продуктов взрыва титановых проводников в пропан-бутане составляет 29580 МПа, что соответствует микротвердости карбида ТіC (28500-33900 МПа, по данным [1]), средняя микротвердость порошков, образованных вольфрамовыми проводниками, составляет $16770 \mathrm{MПа,} \mathrm{то} \mathrm{есть} \mathrm{попадает} \mathrm{в}$ диапазон значений, которыми характеризуется гексагональный монокарбид

WC (13000-25000 МПа, по данным [3]).

\section{ВЫВОДЫ}

Особенностью временных зависимостей напряжения, характеризующих ЭВП рефракторных металлов, является наличие пологого отрезка (плато), образованного в силу относительного постоянства их удельного электросопротивления в жидком состоянии. Увеличение энергетического осаждения в проводниках рефракторных металлов до взрыва, реализованное путем изменения параметров разрядного контура, сопровождается повышением пика перенапряжения и его смещением в сторону более коротких времен.

В титановые проводники при напряжении 25-40 кВ на стадии резистивного нагревания можно ввести порцию энергии, превышающую энергию сублимации проводника в несколько ра3, используя для этого 0,44-0,56\% энергии, накопленной конденсатором. ЭВП с полным испарением более тугоплавкого вольфрама такого же диаметра реализуется при использовании не менее $80 \%$ энергии, накопленной конденсатором.

Экспериментальные данные подтверждают возможность путем ЭВП в органическом газе синтезировать карбидные фазы Ті и W, образованные химическим взаимодействием продуктов взрыва металлических проводников и продуктов пиролиза, прежде всего высокотемпературные карбидные фазы. Порошковые продукты ЭВП состоят из остаточных металлов и карбидов, количество последних увеличивается в смеси с ростом соотношения $E / E_{c}$. Экспериментально $100 \%$ содержание карбидных фаз в продуктах ЭВП получено при условии $E / E_{c} \geq 3$. Монокарбид $\mathrm{TiC}$ является единственным карбидом, образующимся в системе во время электровзрыва титановых проводников. Взрыв вольфрамовых проводников завершается образованием смеси $\mathrm{W}_{2} \mathrm{C}+\mathrm{WC}_{1-\mathrm{x}}$, в которой доминирует стабилизированный при комнатной температуре нестехиометрический кубический карбид $\mathrm{WC}_{1-\mathrm{x}}$.

Образование карбидов тугоплавких металлов происходит даже в условиях, когда введенной на стадии резистивного нагревания проводника энергии недостаточно для того, чтобы перевести его полностью в газообразное состояние, а морфологические особенности продуктов ЭВП свидетельствуют, что процесс карбидообразования проходит преимущественно в жидкой фазе. Продукты ЭВП представляют собой микроразмерные частицы сферической формы с гладкой поверхностью. Наноразмерные фракции порошка оседают на более крупных 
частицах или образуют между собой микроразмерные агломераты. Увеличение энергетического осаждения в проводник и уменьшение его диаметра способствуют уменьшению размера порошковых продуктов.

Микротвердость карбидов титана и вольфрама, полученных путем ЭВП, не является исключительной и соответствует известным значениям микротвердости карбидных фаз этих металлов.

\section{КОНФЛИКТ ИНТЕРЕСОВ}

Авторы заявляют, что у них нет конфликта интересов.

\section{ЛИТЕРАТУРА}

1. Кипарисов, С.С., Левинский, Ю.В., Петров, А.П., Карбид титана: получение, свойства, применение, М.: Металлургия, 1987. 215 с.

2. Гарбузова, А., Галевский, Г., Руднева, В., Ширяева, Л., Анализ современного состояния производства и применения карбида титана, Вестник Сибирского государственного индустриального университета, 2014, т. 1, № 7, с. 34 .

3. Самсонов, Г.В., Витрянюк, В.К., Чаплыгин, Ф.И., Карбиды вольфрама, Киев: Наукова думка, 1974. $176 \mathrm{c.}$

4. Курлов, А., Гусев, А., Фазовые равновесия в системе W-С и карбиды вольфрама, Успехи химии, 2006, т. 75, № 7, c. 687.

5. Liu, N., Kourtakis, K., Figueroa, J., Chen, J., Potential application of tungsten carbides as electrocatalysts: III. Reactions of methanol, water, and hydrogen on Pt-modified C/W(111) surfaces, J. Catal., 2003, vol. 215, no. 2, p. 254.

6. Морозов, М., Акимов, А., Журавков, С., Восьмериков, А., и др., Исследование процесса крекинга гудрона в присутствии катализаторов на основе карбида вольфрама, НефтеГазоХимия, 2017, т. 2, c. 54.

7. Pak, A., Sivkov, A., Shanenkov, I., Rakhmatullin, I., et al., Synthesis of ultrafine cubic tungsten carbide in a discharge plasma jet, Int. J. Refract. Metals Hard Mater., 2015, vol. 48, p. 51.

8. Ильин, А., Назаренко, О., Тихонов, Д., Синтез карбидов металлов электрическим взрывом проводников, Вестник науки Сибири, 2012, т. 3, № 4, с. 80.
9. Debalina, B., Kamaraj, M., Murthy, B., Chakravarthi, S., et al., Generation and characterisation of nano tungsten carbide particle by wire explosion process, J. Alloys Compd., 2010, vol. 496, no. 1-2, p. 122.

10. Tucker, T.J., Toth, R.P., A computer code for the prediction of the behavior of electrical circuits containing exploding wire elements (Report), USA, Sandia laboratories: SAND-75-0041, 1975. 81 p.

11. Zou, X., Mao, Z., Wang, X., Jiang, W., Two different modes of wire explosion for nanopowder production, A Letters J. Exploring the Frontiers of Physics, 2012, vol. 97, p. 1.

12. Sarkisov, G., Sasorov, P., Struve, K., McDaniel, D., State of the metal core in nanosecond exploding wires and related phenomena, J. Appl. Phys., 2004, vol. 96, p. 1674.

13. Rousskikh, A., Baksht, R., Chaikovsky, S., Fedunin, A., et al., The Effects of Preheating of a Fine Tungsten Wire and the Polarity of a High-Voltage Electrode on the Energy Characteristics of an Electrically Exploded Wire in Vacuum, J. of Latex Class Files, 2006, vol. 1, p. 1.

\section{Summary}

A series of electrical explosions in propane-butane of single and strand-connected $\mathrm{Ti}$ and $\mathrm{W}$ conductors with various diameters was carried out. Electrophysical characteristics of the explosion revealed that resistive heating of conductors is characterized by two monotonically ascending sections on the voltage - current curves separated by a flat segment (plateau), which corresponds to relatively stable electrical resistivity of refractory metals in the liquid state. The energy deposited by changing the power input into the conductor during its resistive heating, which can be higher or lower than its sublimation energy and can be regulated by changing the external adjustable parameters of the discharge circuit, is a key indicator determining the structural-phase state of destructed and chemically synthesized products after the explosion. The conditions are achieved under which micro- and nano-sized powder products do not contain residual metals and consist of carbide phases completely (TiC with an average microhardness of $29580 \mathrm{MPa}$ as a result of the titanium explosion and a mixture of $\mathrm{W}_{2} \mathrm{C}+\mathrm{WC}_{1-\mathrm{x}}$, in which stabilized high-temperature nonstoichiometric cubic carbide $\mathrm{WC}_{1-\mathrm{x}}$ dominates, with an average microhardness of $16770 \mathrm{MPa}$ as a result of tungsten explosion).

Keywords: electrical explosion of a conductor, refractory metals, energy deposition rate, sublimation energy, powder, carbides 